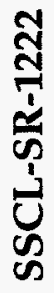

SSCL-SR-1222

June 1993

Distribution Category: 400

L. Cormell

T. Johnson

\title{
ESNET Requirements for Physics Research at the SSCL
}

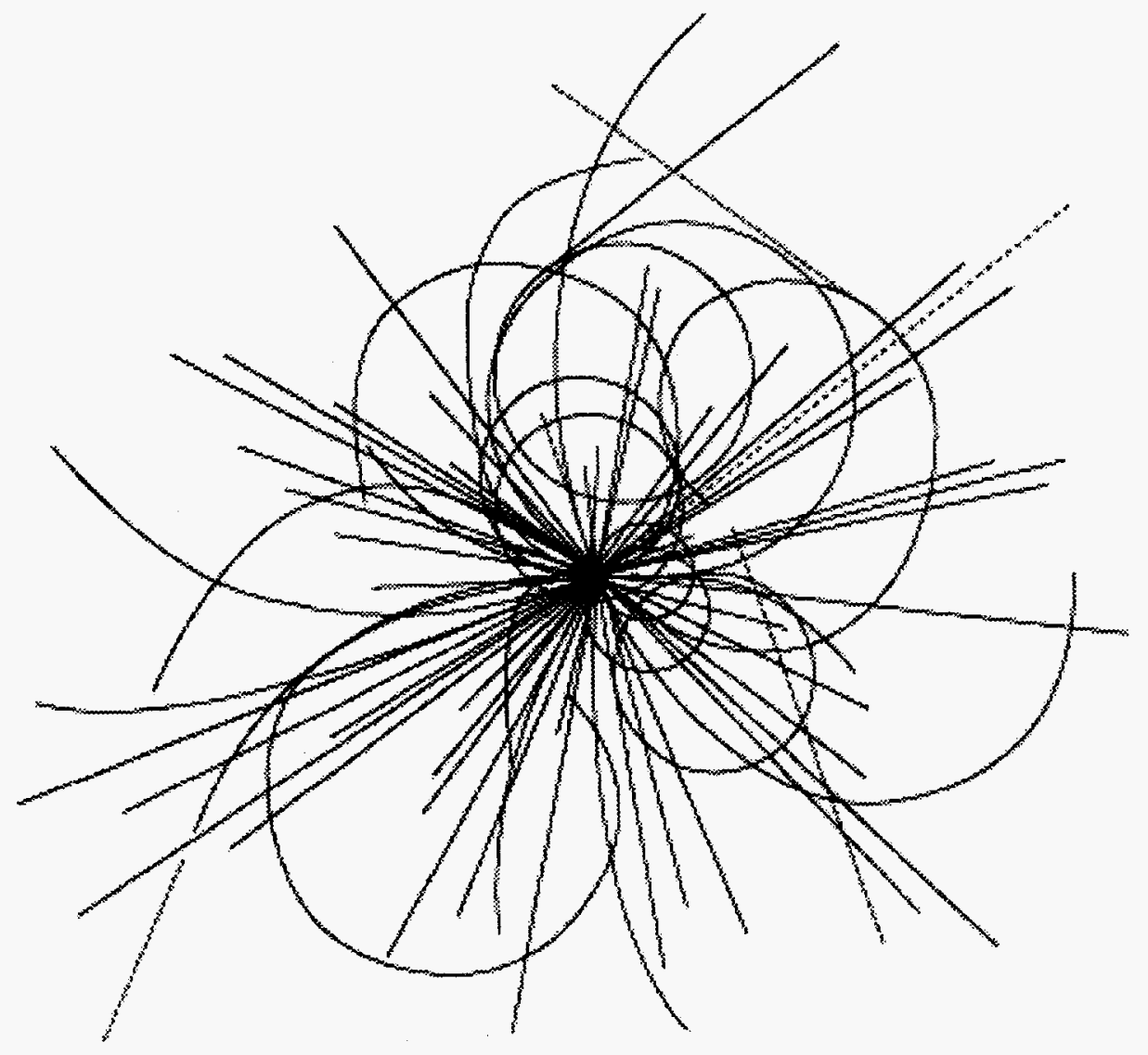

\section{Superconducting Super Collider Laboratory}

APPROVED FOR RELEASE OR PUBLICATION - OR. PATENT GRO
BY.... $9 . . . .$. DATE. $\$ 3 / 5$. 


\section{Disclaimer Notice}

This report was prepared as an account of work sponsored by an agency of the United States Govemment. Neither the United States Government of any agency thereof, nor any of their employees, makes any warranty, express or implied, or assumes any legal liability or responsibility for the accuracy, completeness, or usefulness of any information, apparatus. product, or process disclosed, or represents that its use would not infringe privately owmed rights. Reference herein to any specific commercial product, process, or service by trade name, trademark, manufacturer, or otherwise, does not necessarily constitute or imply its endorsement, recommendation, or favoring by the United States Government or any agency thereot. The views and opinions of authors expressed herein do not necessarily state or reflect those of the United States Government or any agency thereof.

Superconducting Super Collider Laboratory is an equal opportunity employer. 


\section{DISCLAIMER}

Portions of this document may be illegible in electronic image products. Images are produced from the best available original document. 
SSCL-SR-1222

\title{
ESNET Requirements for Physics Research at the SSCL
}

\author{
L. Cormell and T. Johnson \\ Superconducting Super Collider Laboratory* \\ 2550 Beckleymeade Ave. \\ Dallas, TX 75237
}

June 1993

\footnotetext{
* Operated by the Universities Research Association, Inc., for the U.S. Department of Energy under Contract No. DE-AC35-89ER40486.
} 


\subsection{INTRODUCTION AND PURPOSE}

High energy physics (HEP) research at the Superconducting Super Collider Laboratory (SSCL) is a highly collaborative affair. Scientists participating in SSC research come from a worldwide distribution of institutions. The Solenoid Detector Collaboration (SDC) currently has more than 1100 members from 20 countries. Likewise, the Gamma, Electron, Muon (GEM) collaboration members number more than 1000 from 17 countries. Roughly half of the collaborators on these experiments are from outside the U.S. Communications, in general, and data transmission, in particular, are crucial to the success of the collaborations and to the ultimate success of the SSC. The bulk of data transmission to and from the Laboratory is over the Energy Science NETwork (ESNET). The location of the SSCL and its current connections to the ESNET backbone by four T1 lines are shown in Figure 1. The purpose of this document is to describe the anticipated network capacity needed to provide adequate communication among these widespread collaborations.*

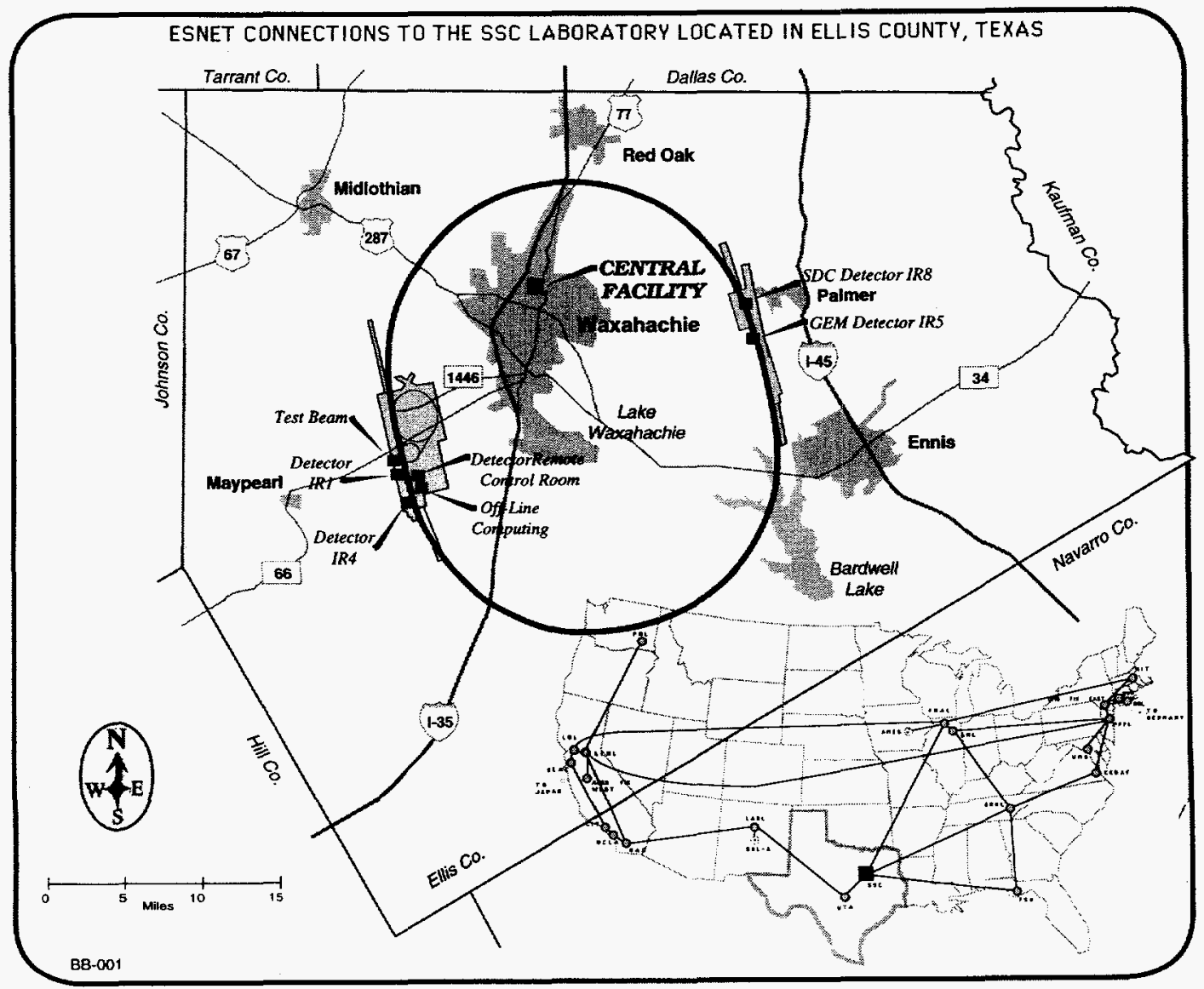

Figure 1. ESNET Connections to the SSC Laboratory.

\footnotetext{
${ }^{*}$ Another set of data communications requirements deals with the need to transmit detector data locally within the SSCL site. These requirements are described in another document.
} 


\subsection{BACKGROUND}

Wide area network (WAN) requirements of the collaborations vary from simple interactive sessions such as e-mail on the low end of the spectrum to the transmission of large amounts of bulk data from the SSCL to the collaborations' regional analysis centers.

The GEM and SDC detectors are being designed to collect and store data at a rate of several gigabits per second (Gbps). The collaborations will analyze much of the detector data at the SSCL and therefore will not require a broadcast of the many petabytes of data to each of the collaborating institutions. Nevertheless, the transmission of reduced samples of data to several regional analysis centers represents a major bandwidth requirement after the SSC becomes operational. At this time, several sources of network transmission over ESNET can be identified, and models for the anticipated ramp-up of the usage can be constructed. The current and anticipated uses of ESNET include:

- Interactive sessions. These sessions currently include users logged into the Physics/Detector Simulation Facility (PDSF) at the SSCL. Some of these sessions are $\mathrm{x}$-window based and some are simply line mode ASCII transmissions. Interactive sessions include activities such as editing, debugging, and e-mail.

- Studio video-conferencing. Since the beginning of the SSCL video-conferencing has been a key form of communication for its distributed collaborations. The Laboratory and its collaborators have established eight video-conferencing studios to date. The savings in travel costs and the increased communication capabilities have shown that videoconferencing is very worthwhile.

- Desktop video-conferencing. Vendors of workstations and PCs are now providing inexpensive video boards and interfaces. With the addition of inexpensive CCD cameras, desktop video-conferencing becomes an extremely attractive alternative to travel/commuting and studio video-conferencing. The usage of desktop videoconferencing coupled with multimedia capabilities and shared white boards should greatly enhance the effectiveness of collaborating scientists throughout the 1990s.

- Multi-media communication. The transmission of digitally recorded graphics, video, and audio segments for memos, reports, and mail is a powerful method of communication. Essentially all computer vendors are now providing multi-media capabilities for their equipment.

- Regional analysis centers. Laboratories such as Fermilab (FNAL), Argonne (ANL), Oakridge (ORNL), and Brookhaven (BNL) are major collaborators on SDC and GEM. A considerable amount of analysis will take place at these labs and at associated universities. Some large fraction of the many petabytes ( $10^{15}$ bytes) of SSC data will be transmitted to these centers.

- Remote control centers. SDC (and possibly GEM) is planning to provide real-time access to the on-line monitoring control and calibration systems of the experiment at several remote centers.

- Test beam data. Detector prototypes will be tested in 1995 and 1996 at Fermilab and at other labs. It is expected that data will be recorded at rates of about 3-5 Mbytes/s, requiring the storage of many terabytes of data. It is planned to transmit this data over ESNET to the SSCL for storage and analysis.

- Other experimental data. Physicists from the SSCL are collaborating on both the CDF and DO experiments at Fermilab. Summary data from both experiments is routinely transmitted to the SSCL. Also, physicists in the SSCL Computing Department generate D0 Monte Carlo data that is transmitted to Fermilab. 
Each of these uses of ESNET is expected to grow at rapid rates and can easily saturate the current capacity of the $\mathrm{T} 1$ backbone.

Ever-increasing bandwidths will be required throughout the development and operation of the SSC. Delays in the improvement of the ESNET to T3, OC-1, and OC-12 capabilities would cause a tremendous detriment to the capability of producing timely, high-quality research from the SSC.

\subsection{MODEL OF NETWORK USAGE}

It is anticipated that the SSC requirements for ESNET will grow rapidly from current rates of $1 \mathrm{Mbps}$ or so to rates in excess of several Gbps. To plan for those needs and to determine the impact they may have on the national information infrastructure, we have developed a model that attempts to estimate the growth over a period of 10 years. The model is based on the uses of the network described in the previous section, the number of participating scientists and their distribution, and the predicted data collection and analysis requirements for SSC detectors.

\subsection{Assumptions}

A number of simplifying assumptions have to be made in order to predict the growth of network usage. These include:

- Schedule. The main factors in determining the schedule for large data-transmission requirements are the startup of test beam activities at FNAL and at the SSCL, and the beginning of the SSC operation. These dates are assumed to be FY 1995, FY 1997, and FY 2000, respectively. Other requirements, such as desktop televideo, simply start now and basically increase with time.

- Media. It is assumed that all of the data transmission described in this note will be over ESNET or follow-on networks in the national information infrastructure, such as NREN. While it is conceivable that some of this traffic may be carried by commercial or FTS telephone circuits, that assumption is not made here.

- Interactive usage. User accounts on the PDSF currently number about 500 and on SSCVX1 about 1500 . Nearly one-half of these accounts are external users. The number of external accounts is expected to grow to about $1500-2000$. Typically, about $10-20 \%$ of the users are actively using the systems during the day. Much of the network activity is simple command line input and transmission of small amounts of data, but an everincreasing amount of the traffic is $\mathrm{X}$-window based. It is assumed that eventually all interactive usage will be $x$-based, requiring a bandwidth of $40-100 \mathrm{~KB} / \mathrm{s}$ per session.

- Studio video-conferencing. It is assumed that studio video-conferencing traffic will grow linearly or slightly faster throughout the development of the SSC. It is anticipated that the bandwidth per channel ( $128 \mathrm{Kbps}$ ) will remain constant and that video quality will be improved over the years by improved compression algorithms.

- Desktop video-conferencing. It is expected that traffic from desktop video-conferencing will grow exponentially for the next few years. Depending upon the frame rate and the compression algorithms being used, a two-way session may require a bandwidth of $30-100 \mathrm{Mbps}$. It is assumed that this mode of communication will eventually become the preferred mode rather than telephone or e-mail.

- Multi-media. Multi-media usage is likely to grow exponentially for the next few years but increase at a slower rate of growth thereafter. A typical multi-media transmission might be a memo with an enclosed video, graphics, or audio clip of perhaps 1-100 MB of data. Eventually several thousand people are likely to transmit multi-media messages. Multi- 
media transmissions are likely to replace or become what is currently e-mail communication.

- Regional centers. It is assumed that about $10 \%$ of the detector data collected at the SSCL will be transmitted to the collaborations' regional centers.

- Remote control centers. It is assumed that data equivalent to about $10 \mathrm{x}$-window sessions and 5-10 televideo sessions will be transmitted to each of four regional control centers during the operation of the SSC.

\subsection{Predictions}

The predicted usage and growth of ESNET by the SSCL and its collaborators is summarized in Table 1 and is graphically represented in Figure 2 . In this model the network traffic is eventually dominated by transmission of data to the regional analysis centers and the remote control centers following the startup of the SSC experimental program. Second to those combined uses is the desktop video-conferencing, which is assumed to be a key factor in providing the daily communication necessary to plan, design, configure, install, and run the experiments. Transmission of data from the test beams to the SSCL represents the dominant requirement in the near term (FY 1995-97).

TABLE 1. ESTIMATED ESNET BANDWIDTH REQUIREMENTS (Mbps).

\begin{tabular}{|c|c|c|c|c|c|c|c|c|c|}
\hline & 1994 & 1995 & 1996 & 1997 & 1998 & 1999 & 2000 & 2001 & 2002 \\
\hline $\begin{array}{l}\text { Studio Video- } \\
\text { conferencing }\end{array}$ & 0.5 & 0.8 & 1.0 & 2.5 & 5.0 & 10 & 20 & 30 & 40 \\
\hline $\begin{array}{l}\text { Desktop Video- } \\
\text { conferencing }\end{array}$ & 10 & 20 & 40 & 100 & 500 & 1000 & 1500 & 2000 & 2500 \\
\hline Multi-Media & 0.5 & 0.5 & 0.7 & 2.0 & 10 & 40 & 60 & 75 & 100 \\
\hline $\begin{array}{l}\text { Bulk Data- } \\
\text { Regional Centers }\end{array}$ & 1.0 & 5.0 & 10 & 15 & 40 & 100 & 200 & 400 & 500 \\
\hline $\begin{array}{l}\text { Remote Control } \\
\text { Centers }\end{array}$ & 0 & 0 & 100 & 200 & 400 & 800 & 1600 & 3200 & 4000 \\
\hline $\begin{array}{l}\text { Interactive } \\
\text { Sessions }\end{array}$ & 10 & 20 & 30 & 40 & 50 & 40 & 30 & 20 & 10 \\
\hline $\begin{array}{l}\text { Test Beam and } \\
\text { Test Bed }\end{array}$ & 1.0 & 50 & 100 & 100 & 150 & 150 & 150 & 150 & 150 \\
\hline Other Experiments & 4.0 & 0.5 & 0.5 & 5.0 & 5.0 & 0.5 & 0.5 & 5.0 & 5.0 \\
\hline TOTALS & 27 & 97 & 282 & 465 & 1160 & 2141 & 3561 & 5880 & 7305 \\
\hline
\end{tabular}




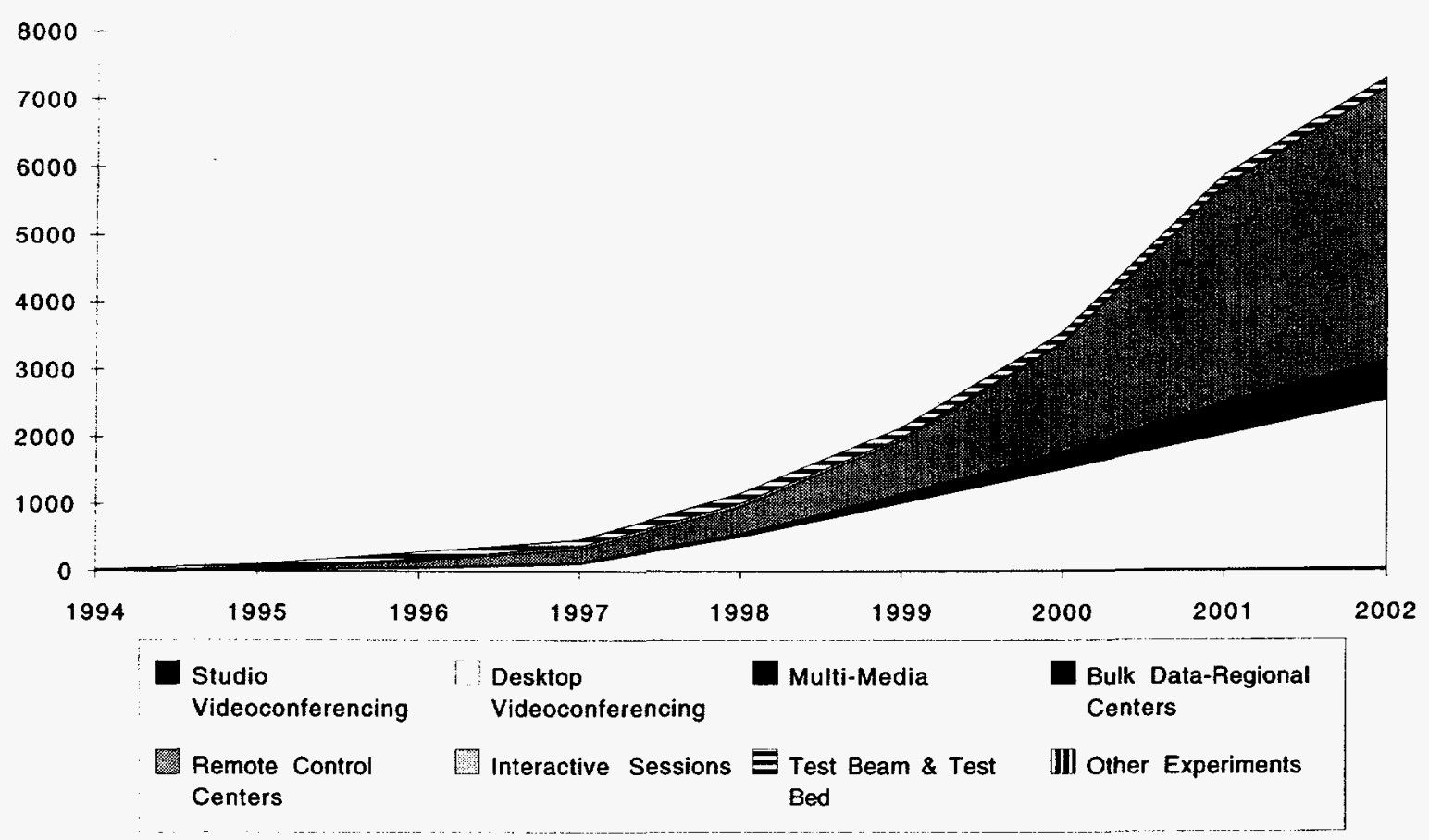

Figure 2. Physics Communications Requirements in $\mathrm{MB} / \mathrm{s}$.

\subsection{CONCLUSIONS}

The SSCL currently has four T1 connections at $1.5 \mathrm{Mbps}$ each to ESNET, as shown in Figure 1 . It is likely that T1 bandwidth will meet the communications needs for perhaps the next year or so. Early in 1995, both GEM and SDC are scheduled to begin test beam operation at FNAL. The bulk of this data will be transmitted back to the computing "ranch" at the SSCL for storage and analysis. At that time it is anticipated that the Laboratory and in particular the Physics Research Division will need the equivalent of three or more T3 lines at $45 \mathrm{Mbps}$ each. At least one of these will be dedicated to the Fermilab test beams. By 1997 the bandwidth requirement is expected to grow to the OC-12 level (622 Mbps). Based on this model it is anticipated that early in the next century the Laboratory will require a network backbone capable of supporting traffic in excess of OC-48 rates ( $2.4 \mathrm{Gbps})$. 